\title{
NOTES ON SOME GROWTH CHARACTERISTICS OF MIKANIA CORD AT A (BURM. F.) B.L. ROBINSON*)
}

\author{
B.T. MERCADO \\ Institute of Biological Sciences, University of the Philippines at Los Banos, \\ College, Laguna, Philippines
}

\begin{abstract}
Mikania follows a sympodial dichotomy pattern of branching. Both stem (branches) and leaves give rise to new plants with relative ease. Internodes also root easily but do not give rise to new plants. Flower formation and seed germination are strongly influenced by light. Numerous seeds are produced but only few are filled; still fewer are the seeds that germinate. The period from early emergence to about the 3-leafed stage is most critical for survival of the new plant.
\end{abstract}

Keywords: Mikania cordata, Growth, Weed physiology

\section{INTRODUCTION}

Mikania cordata (Burm. f.) B.L. Robinson, a creeping woody perennial is popularly known by its local names of climbing hempvine and mile-a-minute plant. It is described systematically in the compendium of the World's Worst Weeds (Holm et al. 1977).

The stem (and its branches) and the mature leaves easily form roots when these come in contact with the soil (Figs, la $\&$ b). The leaves on the creeping stem or branch are strongly negatively geotrophic. If a portion of the stem or branch is twisted to bring the leaves to face the soil, overnight the leaves would be upright, held up by the petioles that had curved upward (Fig. 2).

\section{Pattern of branching}

Branching follows a sympodial dichotomy (Fig. 3). The stem produces a terminal shoot which dries up after some time. At its closest node emerges the first pair of branches which elongates. On these branches are borne several nodes. The

*) The project was supported by a grant from the National Research Council of the Philippines (NRCP). 
Notes on some growth characteristics of Mikania cordata - B.T. Mercado

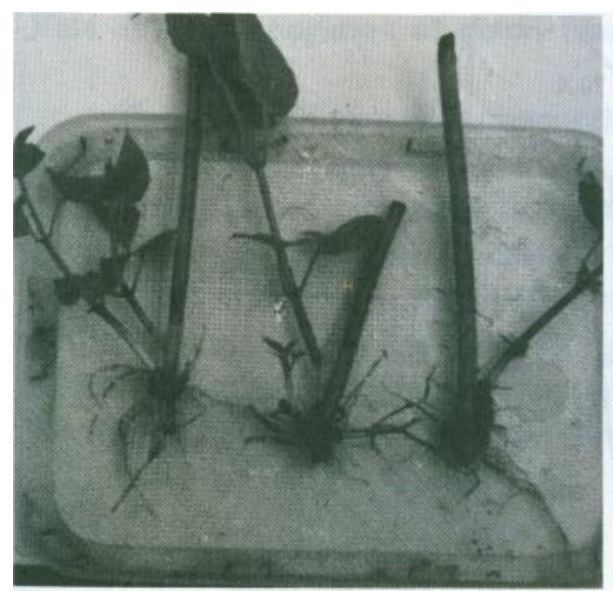

la



$\mathrm{Ib}$

Fig. 1. New plants arising from stem (a) and leaf (b) cuttings

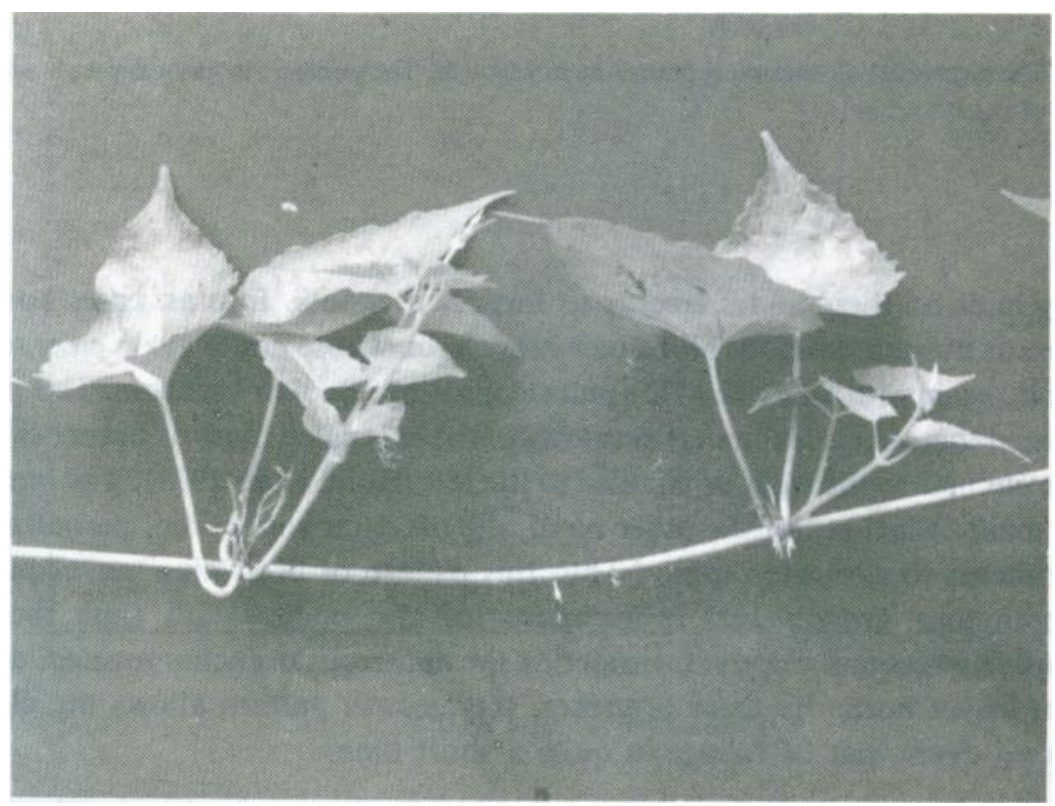

Fig. 2. The upright bended petioles and nodal roots pointing upward indicate the strong negative geotrophic characteristic of leaves and stem 


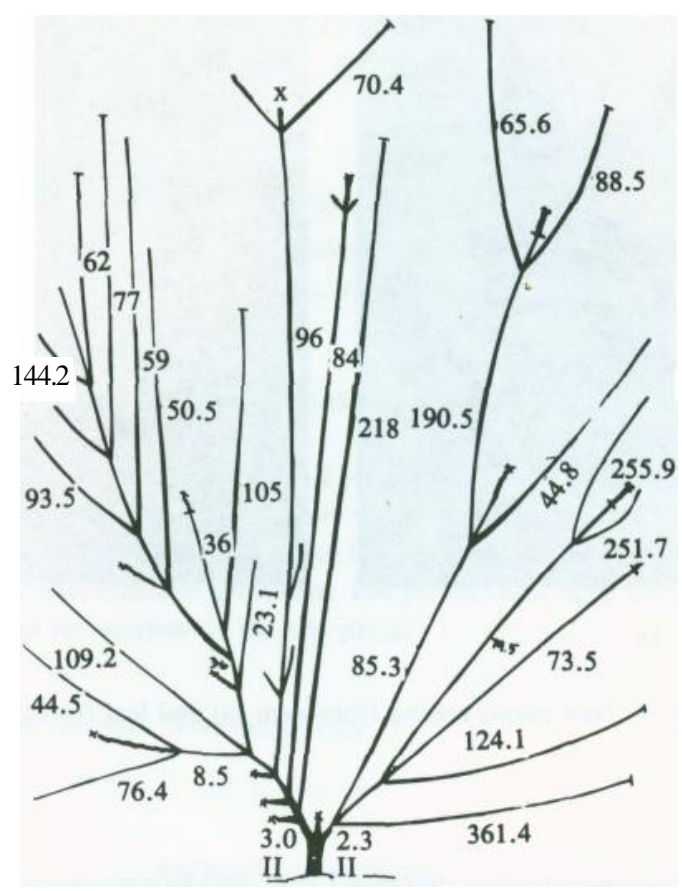

Fig. 3. The sympodial dichotomous branching in Mikania. The numbers indicate approximate length of the branches

axillary buds on these nodes emerge to form new shoots. In most cases however, only one of the pair develops into a new branch, on whose nodes again emerge pairs of shoots, again with only one of the pairs elongating into new branches. This pattern is repeated thereafter, ultimately resulting in the entangled mass of branches which may be circular to the right or circular to the left (Holm et al. 1977). The terminals of the main branches, on the other hand, die off after some time, permitting the side branches to elongate rapidly. Thus this pattern of branching makes possible the continuous growth and rejuvenation of the plant. With time the stem progressively becomes woody. Considering the numerous branches formed, and the bulk of leaves borne by these branches, this growth pattern allows the plant to produce a dense mat of foliage in quite a short time. 


\section{Rate of stem elongation of plants from leaf and stem cuttings}

The data in Figure 4a represent the observations from 10 plants grown from leaf cuttings, while those in Figure 4b, from 13 plants grown from stem cuttings. In both cases, the first branch that came out from the rooted cutting was tagged for the daily or weekly measurements. The branches of the leaf cuttings elongated much more rapidly than the similar branches of the stem cuttings. These were at its longest on the 26 th day after the first measurement. These ceased to elongate after this date. Three (3) tagged branches of the stem cuttings died off 39 days after the initial measurement, while the rest, after the $68^{\text {th }}$ day.



Fig. 4 Rate of elongation of the first branch from leaf (a) and stem cutting (b) 


\section{Effect of sunlight on rate of stem elongation}

Three plants raised from seeds were grown under direct sunlight and another three plants, under partial shade. (A makeshift enclosure roofed by 2 layers of fishnets served this purpose). The plants were observed daily for 21 days after the 5-leafed stage. As before, the first branch that emerged was tagged and measured daily until the elongation of the branch decreased or stopped in any of the light treatments.

Under partial shade (Fig. 5a) the branches elongated much more rapidly than those under direct sunlight (Fig. 5b). Its elongation continued even after the 20th day, while the elongation of branches under direct sunlight completely stopped on the 18th day after the initial measurement. The number of nodes borne on the tagged branches of both sets of plants did not differ very much from each other, although node count was slightly higher in the branches of the plants under partial shade.



Fig 5. Elongation of the first branch from a seed-grown plant exposed to (a) partial shade and (b) direct sunlight 
The biomass productions after a six-month growth period under partial shade or direct sunlight of plants grown from cuttings are given in Table la (stem cutting) and in Table $1 \mathrm{~b}$ (leaf cutting). In both light treatments, the shoot dry weight of the plants under partial shade was 2-5 times higher than those of the plants grown under direct sunlight. Light apparently did not influence the dry matter production of the roots. Surprisingly, however, the root system of the plant was not profuse and long as might be expected of a plant capable of producing such dense vegetative growth (Fig. 6a). This may be due in part to the fact that the creeping stem or branch readily produces two kinds of roots: the usual nodal roots, and the internodal roots (Fig. 6b). Undoubtedly, anchorage as well as absorption of nutrients and water is a function well carried out by these stem-borne roots. There are not very many creeping plant species, succulent or woody, that develop internodal roots.

On the whole, the plants grown under partial shade are much more vegetative, luxuriant and green than the plants grown under direct sunlight. The plants under partial shade remain vegetative. On the other hand, those which are exposed to sunlight start to flower in mid November until late January. Field observation also showed that even in the same plant, the shaded portion remains vegetative while the upper portion exposed directly to sunlight produces flowers profusely.

\section{The seed}

The seeds are elongated, $1.5-1.8 \mathrm{~mm}$ in length and about $0.3-0.4 \mathrm{~mm}$ at its widest. These are black, with a longitudinal ridge in the middle, tufted at one end with pappus (about 40 - 50 hairs). The pappus adds about $3.0 \mathrm{~mm}$ to the length of the seed. The seed is filled with white endosperm. Red ants are common foragers of ungerminated seeds. The seed dries up easily if kept in the open air. It has a very short period of viability.

Table la. Dry weight $(\mathrm{g} / \mathrm{p})$ of Mikania grown from stem cuttings under partial shade or direct sunlight (6 Feb.-Sept. 1991)

\begin{tabular}{lllll}
\hline Plant & & Partial shade & \multicolumn{2}{c}{ Direct sunlight } \\
No. & Shoot & Root & Shoot & Root \\
\hline 1 & 135.7 & 3.2 & 38.5 & 2.2 \\
2 & 136.0 & 2.3 & 17.2 & 1.4 \\
3 & 176.6 & 3.1 & 27.0 & 2.1 \\
4 & 95.6 & 2.2 & 30.0 & 3.0 \\
5 & 176.6 & 1.4 & 25.6 & 1.4 \\
\hline Average & 144.1 & 2.44 & 27.66 & 2.02
\end{tabular}


BIOTROPIA No. 7, 1994

Table 1b. Dry weight $(\mathrm{g} / \mathrm{p})$ of Mikania grown from leaf cuttings under partial shade or direct sunlight (11 March-9 Sept. 1991)

\begin{tabular}{llllll}
\hline $\begin{array}{l}\text { Plant } \\
\text { No. }\end{array}$ & Shoot & Partial shade & \multicolumn{2}{c}{ Direct sunlight } \\
\hline 1 & 170.5 & Root & Shoot & Root \\
2 & 81.5 & 2.5 & 46.0 & 2.0 \\
3 & 63.5 & 2.3 & 40.0 & 1.3 \\
4 & 65.6 & 1.4 & 43.0 & 2.3 \\
5 & 85.3 & 2.2 & 35.0 & 1.6 \\
\hline Average & 93.28 & 3.8 & 43.5 & 2.9 \\
\hline
\end{tabular}

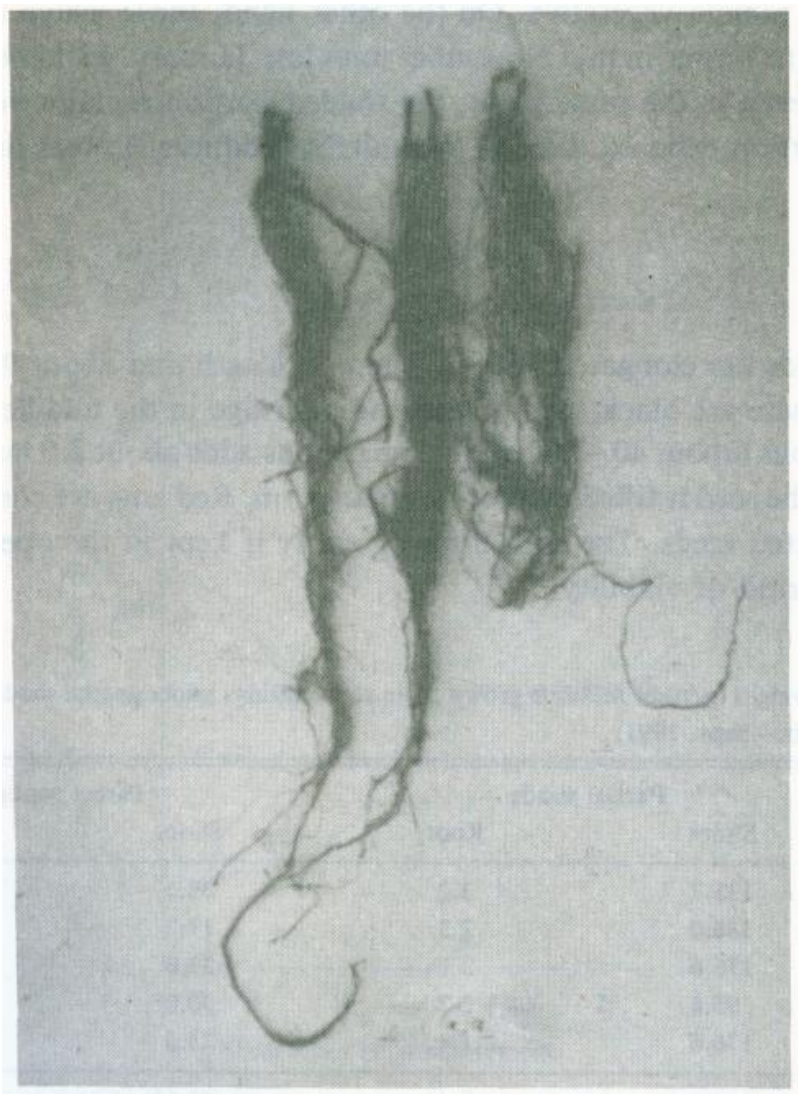

Fig. 6a. The main root system of Mikania plant 




Fig. 6b. The nodal and internodal roots of a creeping stem of Mikania

\section{Seed count and seed germination}

A panicle has as many as 134-428 seeds (Table 2), but the number of filled seeds is very low (6.52 - 27.62\%). Similar observation was reported by Wirjahardja (1976) in the three Mikania species common in Indonesia.

Fifteen (15) filled seeds were sown in petri dish lined with moist filter paper. Four (4) dishes were completely wrapped with two layers of carbon paper, while another four (4) uncovered dishes were placed on a lighted laboratory table. Germination took place within three days in the light-exposed dishes. The carbon paper-wrapped dishes, opened seven days after sowing the seeds, showed complete failure of germination. The germination of the light-exposed seeds (Table 3) was very low. Repeated trials failed to exceed 50\% germination even when the germination period was extended for another week.

Soil germination trials showed that seeds slightly buried into the soil (sticking the whole $1.5-1.8 \mathrm{~mm}$ length of the seed into the moist soil) failed to germinate, while seeds, laid flat on its side on the surface of moist soil germinated within a few days. 
Table 2. Number of seeds (cypsela) per panicle

\begin{tabular}{lllll}
\hline Panicle No. & $\begin{array}{l}\text { Filled } \\
\text { seeds }\end{array}$ & $\begin{array}{l}\text { Unfilled } \\
\text { seeds }\end{array}$ & Total & $\%$ filled \\
\hline 1 & 21 & 301 & 322 & 6.52 \\
2 & 41 & 227 & 268 & 15.29 \\
3 & 25 & 183 & 208 & 12.02 \\
4 & 25 & 317 & $342^{\prime}$ & 7.31 \\
5 & 37 & 97 & 134 & 27.61 \\
7 & 43 & 385 & 428 & 10.04 \\
8 & 39 & 239 & 278 & 14.03 \\
\hline
\end{tabular}

Table 3. Germination of Mikania seed (15 seeds per petri dish)

\begin{tabular}{lcl}
\hline Replication & $\begin{array}{c}\text { No. of seeds } \\
\text { germinated }\end{array}$ & $\begin{array}{l}\text { Germination } \\
\%\end{array}$ \\
\hline 1 & 4 & 26.6 \\
2 & 4 & 26.6 \\
3 & 6 & 40.0 \\
4 & 6 & 40.0 \\
\hline
\end{tabular}

The above observations suggest that although a Mikania plant (one exposed to sunlight) has the propensity to produce numerous seeds which could be dispersed at great distance, only a handful of these seeds are filled, and only a few of them are viable. For the viable seeds to germinate light is indispensable.

\section{The seedling}

The seedling emerges from the pole directly opposite the pappus-bearing pole of the seed. The thin, long primary root comes out first. The root tip is distinctly covered with a black root cap. Conspicuous is the tuft of short, fine and sticky roots borne at the base of the hypocotyl. These roots would later on constitute the root system of the plant, replacing the long primary root that dies off after some time.

The hypocotyl is much bigger in diameter than the spindly primary root but a little shorter. The hypocotyl of the newly emerged seedlings had an average length of $0.97 \mathrm{~cm}$. In another 12 days, however, it had already an average length of 21.83 
$\mathrm{cm}$, about twice longer than the primary root. At one end of the hypocotyl the pair of round, green, succulent cotyledons is borne. The cotyledons remain intact on the seedling until the young plant has attained the 3-leafed stage. The seedling, from germination to the early early 3-leafed stage is most vulnerable to wilting. However, once it has survived this critical period it develops rapidly into a mature and highly vegetative plant.

\section{SUMMARY}

Mikania has a well developed and efficient means of vegetative reproduction (Fig. 7). A portion of the mature stem or branch (IV-1), as long as it bears a node, easily gives rise to a new plant. With similar ease, the mature leaves can also give rise to new plants (IV-3). An internodal stem or branch (one which does not bear a node), easily forms roots but does not give rise to a new plant (IV-2).

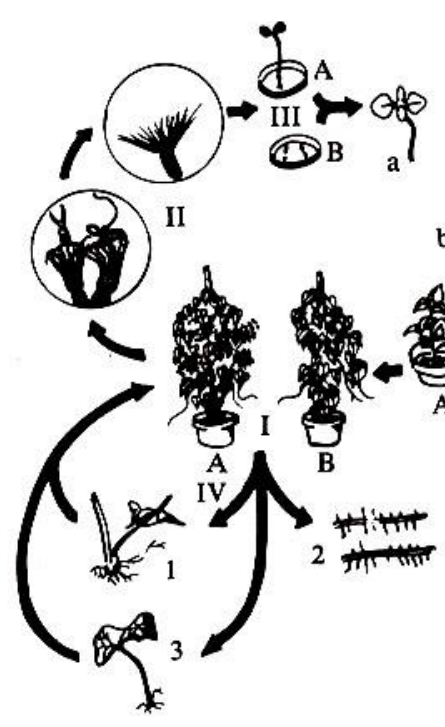

I. A. Direct sunlight

B. Partial shade

II. Inflorescence and cypsela

III. A. Direct sunlight

B. Dark

a. 2-leafed stage

b. 3-leafed stage

c. 5-leafed stage

IV. 1 . Stem cutting with node

2. Stem cutting without node

3. Leaf cutting

Fig. 7. The life cycle of Mikania cordata 
The development of the plant, whether derived from cuttings (I) or from seeds (III) is strongly influenced by light. The plant grown under partial shade elongates very rapidly, is dark green and luxuriant. It remains however, vegetative (I-B). In contrast, the plant grown under direct sunlight, develops less densely but comes to profuse bloom in mid-November until late January (I-A). Numerous seeds are produced but only a few are filled, and fewer still are viable. The pappus-bearing, minute seeds (II) are dispersed by wind. For the seed to germinate, light is indispensable. For the seedling to survive it must be located in a moist and shaded area.

\section{REFERENCES}

HOLM, LG., D.L. PLUCKNETT, J.V. PANCHO, and J.P. HERBERGER, 1977. The World's Worst Weeds. University Press. Hawaii, Honolulu.

WIRJAHARDJA, J. 1976. Autecological study of Mikania spp. Proceedings of the Fifteenth Asian-Pacific Weed Science Society Conference. Tokyo, Japan. Asian-Pacific Weed Science Society. 